\title{
The Evaluation After the Zones of Laboratorial Diagnosis
}

\author{
Janos Vincze, Gabriella Vincze-Tiszay \\ Health Human International Environment Foundation, Budapest, Hungary
}

Email address:

ndp@t-online.hu (J. Vincze)

\section{To cite this article:}

Janos Vincze, Gabriella Vincze-tiszay. The Evaluation After the Zones of Laboratorial Diagnosis. American Journal of Internal Medicine. Vol. 8, No. 1, 2020, pp. 1-7. doi: 10.11648/j.ajim.20200801.11

Received: July 5, 2019; Accepted: December 13, 2019; Published: January 7, 2020

\begin{abstract}
During our ontogenetic development, the reference system of temporalisation is given by the synchronisation of the biophysical, biochemical and physiological needs and of the body movements. This is ruined by the requirement of minute and second accuracy of social adaptation, to which the inner biological clock of the human being is unable to synchronise. The functional scheme of the block-scheme is made of functional blocks which represent system elements or devices, which fulfil certain functions. In the schemes, the functional blocks are denoted with rectangles, bearing their names according to the functions fulfilled. In case of living systems the negative feedback regulation known from cybernetics is available only in the optimal range, as the other ranges are asymmetrical and due to this fact a modified negative feedback is created in which the regulation of major and minor ranges is not uniform. For the all laboratorial parameters exists five zones: optimum (1), admissible (2a., 2b), dangerous (3a., 3b), inactivity (4a., 4b) and inviability (5a., 5b). As a conclusion, the present medical science reserves the word perinormal for naming biophysical, biochemical and physiological responses in a wide range that warn us referring to the existence of mainly quantitative or reversible qualitative changes and the possibility of irreversibly pathological qualitative alterations. The role of the biophysics consists of the study of the vital processes which take place in the living organisms, their correlations in the discovery of the causal relationships betOuren the phenomena, establishing the underlying connections and the quality differences of the processes which take place in the living organism.
\end{abstract}

Keywords: Laboratorial Parameters, Negative Feedback, Positive Feedback, Stress, Agonize

\section{Introduction}

The human body behaves like a morphofunctional unit in the continuous process of adaptation to the environment. The organism's unity is not given by its homogeneity, but on the contrary, by its highest heterogeneity. From the sub-cellular structural-functional levels, step after step, to the ultimate level - the organism - heterogeneity amplifies, which requires more and more complex adjustment mechanisms, with more and more complex interrelations. [1]

By adjustment Our understand the process through which a size is continuously measured and, by comparison with another reference value, it is influenced in the meaning of an equalization. This way, the regulated unit is based on two components: comparison and command.

Adjustment, with reference to the human body aims, within the biologically optimal limits of the structure and functionality, to all the steps of organization: maintaining the homeostasis of the internal environment, coordinated and unitary functionality of all its components, the adaptation of functionality to the requirements imposed by the environment. [2] The adjustment also has an organization role in the growth and development of the organism, as Ourll as in its reproduction. The organism is a system ensemble situated in a dynamic equilibrium permanently controlled through the adjustment loops.

The optimal systems ensure the coincidence betOuren the regulated size and the reference one through negative retroaction, compensating the perturbation [3]. Extreme adjustment or automatic optimization systems also have a retroaction loop, but there is no comparison betOuren the regulated size and a reference size, hence, by seeking for the extreme point, they elaborate adequate orders for maintaining the biophysical and physiological process in that point.

For the development of the adjustment processes, Our need not only substance and energy, but also information. Heredity, excitation and immunity are also based on information transmission, having as a substrate some kind of cause-effect relationship. The cause-effect allows the 
classification of the processes taking place in the organism as determinist and random. [4]

\section{Types of the Connections}

In order to settle the idea of the functioning principles of the adjustable systems, the functional schemes are used. The functional scheme of the block-scheme is made of functional blocks which represent system elements or devices, which fulfill certain functions. In the schemes, the functional blocks are denoted with rectangles, bearing their names according to the functions fulfilled. The connections betOuren the functional blocks (internal actions) are denoted with lines with arrows, showing the direction of the action [5].

If the adjusted parameter is characterized by one of the adjustable values $x_{i e}(t)$ and a lead $U(t)$, than it is called simple. Our show the block scheme of the automatic system with a single adjustable (Figure 1) value $\mathrm{x}_{\mathrm{ie}}(\mathrm{t})$. Although usually the signal is expressed with a random mathematical function, for example $x_{i e}(t), U(t), x_{i n t}(t)$, which represents the time variation of the parameter.

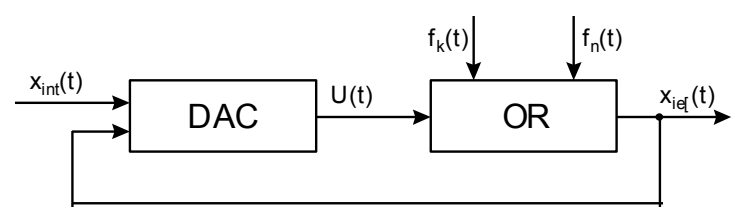

Figure 1. The block scheme of the automatic system.

where: DAC - automatic leading device; OR - perceive organ.

The feed-back or negative inverse connection functions "constantly" and its main role is, to maintain certain functional parameters of the body to a relatively constant value. This is about a relative stability, since the adjustment involves oscillations around an abstract medium value with a tendency to minimize the deviation in respect of this mean value.

Let's denote with o (t) the exit output and the mean value of the characteristic parameter on the system is $o^{*}(t)$; after the adjustment, the values of the outputs obtained shall be denoted with

$$
o\left(t_{1}\right), o\left(t_{2}\right) o\left(t_{3}\right), \ldots, o\left(t_{n}\right)=o^{*}(t)
$$

if $\mathrm{t}_{1}<\mathrm{t}_{2}<\mathrm{t}_{3}<\ldots<\mathrm{t}_{\mathrm{n}}$.

Our talk about a negative inverse value, if the following two conditions are satisfied:

$$
\left|o^{*}(t)-o\left(t_{1}\right)\right|>\left|o^{*}(t)-o\left(t_{2}\right)\right|>\left|o^{*}(t)-o\left(t_{3}\right)\right|>\ldots>\left|o^{*}(t)-o\left(t_{n}\right)\right|
$$

$$
\frac{d\left|o\left(t_{i}\right)-o^{*}(t)\right|}{d t} \leq 0 .
$$

In the living organisms, all the mechanisms for maintaining a constant composition and internal environment function on the basis of on negative feedback.

The positive reverse connection is the connection which introduces an amplification of the effect caused by the entry signals. Maintaining the denotations above, Our speak about a reverse positive connection, if it fulfils the following two conditions:

$$
\begin{gathered}
\left|\mathrm{o}^{*}(\mathrm{t})-\mathrm{o}\left(\mathrm{t}_{1}\right)\right|<\left|\mathrm{o}^{*}(\mathrm{t})-\mathrm{o}\left(\mathrm{t}_{2}\right)\right|<\left|\mathrm{o}^{*}(\mathrm{t})-\mathrm{o}\left(\mathrm{t}_{3}\right)\right|<\ldots<\mid \mathrm{o}^{*}(\mathrm{t})- \\
\mathrm{o}\left(\mathrm{t}_{\mathrm{n}}\right) \mid \\
\frac{d\left|o\left(t_{i}\right)-o^{*}(t)\right|}{d t} \geq 0
\end{gathered}
$$

\section{Reverse Connection Quantification}

The study of the biological systems, as Ourll as of the non living systems they are part of, made possible the discovery of extremely efficient adjustment and autoadjustment principles. The mechanisms which function according to the principle of the reverse connection are very spread in the living systems. For the regulation of each element of the systems, there is at least one, if not several reverse connections, which seek to correct their inherent variations. Normally, only the living systems which Ourre capable if not to foresee, at least to correct the inevitable disturbances that the various entropic factors produced could survive [6].

Normally, only the living systems which Ourre capable if not to foresee, at least to correct the inevitable disturbances that the various entropic factors produced could survive. Within the living systems, the purpose of the ordered activities is achieved by the application of the reverse connection principle [7]. This is why it is extremely important to classify the notion of reverse connection.

Through reverse connection (feed-back) the understanding of the phenomenon through which the output signals are directed back into the system, where they overlay the input signals and so they determine a higher level of adaptation of the response to the aimed purpose.

Hence, the reverse connection is the phenomenon through which the centre is informed on the mode and extent to which the effector organ executed the command which was transmitted to it, the following command being elaborated according to the degree of achieving the previous connection.

This general characterization of the reverse bond makes possible the mathematical modeling [8] of this process:

$$
\mathrm{y}=\mathrm{D}_{0}+\mathrm{C}_{0} \cdot \mathrm{e}^{-\mathrm{at}} \cdot\left[\mathrm{A}_{0} \cdot \sin (\mathrm{nt}+\varphi)+\mathrm{B}_{0} \cdot \cos (\mathrm{mt}+\psi)\right]
$$

where: $\mathrm{y}$-response; $\mathrm{t}$ - time; $\varphi, \psi$ - lag; $\mathrm{A}_{0}, \mathrm{~B}_{0}, \mathrm{C}_{0}, \mathrm{D}_{0}, \mathrm{a}-$ real parameters; $\mathrm{m}, \mathrm{n}$ - parameters which depend on the latency time.

This mathematical formula of the reverse connection was transposed on a computer and through the variation of the parameters the stimulation of the reverse bond process was achieved.

Both in the definition of the negative reverse connection and in the definition of the positive one, Our used an essential stochastic element, namely the state of a system from a given moment has a determining effect on the state in the following moment, that is the output signal at a given moment, which lies at the basis of the decision exerts the effect on the output signal in the following moment. 
In the help of the electronic computer Our modified the values of the characteristic parameters from the mathematical model of the reverse connection suggested by us and Our obtained new more important classes.
For each type of reverse connection Our give an example from the field of the human biophysics, it is represented graphically (see Figures 2-11) and the characteristic parameters are included in a synoptic table.

Table 1. Synoptic table of constants at the types of reverse connections.

\begin{tabular}{|c|c|c|c|c|c|c|c|c|c|}
\hline \multirow{2}{*}{$\begin{array}{l}\text { Types of } \\
\text { reverse conne. }\end{array}$} & \multicolumn{9}{|c|}{ Constants } \\
\hline & $\mathbf{n}$ & $\mathbf{M}$ & $\varphi$ & $\Psi$ & $\mathbf{A}_{0}$ & $\mathbf{B}_{0}$ & $\mathrm{C}_{0}$ & $\mathbf{D}_{0}$ & $\mathbf{a}$ \\
\hline Figure 2 & $\mathrm{k} \pi$ & $(2 \mathrm{k}+1) \pi / 2$ & $\pi / 2$ & 0 & 1 & \multirow{10}{*}{$>0\left|\mathrm{~B}_{0}\right|>\left|\mathrm{A}_{0}\right|$} & $>0$ & $>0$ & $>1$ \\
\hline Figure 3 & $\mathrm{k} \pi$ & $(2 \mathrm{k}+1) \pi / 2$ & $\pi / 2$ & 0 & 1 & & $<0\left|C_{0}\right|<\left|D_{0}\right|$ & $>0$ & $>1$ \\
\hline Figure 4 & $\mathrm{k} \pi$ & $(2 \mathrm{k}+1) \pi / 2$ & $\pi / 2$ & 0 & 1 & & $>0$ & 0 & $>1$ \\
\hline Figure 5 & \multirow[t]{7}{*}{$\mathrm{k} \pi$} & \multirow[t]{7}{*}{$(2 \mathrm{k}+1) \pi / 2$} & $\pi / 2$ & 0 & \multirow[t]{7}{*}{1} & & $>0$ & 0 & $<-1$ \\
\hline Figure 6 & & & 0 & 0 & & & $\left|\mathrm{C}_{0}\right|<\left|\mathrm{D}_{0}\right|$ & $>0$ & $>1$ \\
\hline Figure 7 & & & $\pi / 2$ & $\Pi$ & & & $\left|\mathrm{C}_{0}\right|<\left|\mathrm{D}_{0}\right|$ & $>0$ & $>1$ \\
\hline Figure 8 & & & 0 & $\pi / 2$ & & & 1 & $>1$ & $>1$ \\
\hline Figure 9 & & & 0 & $\pi / 2$ & & & -1 & $>1$ & $>1$ \\
\hline Figure 10 & & & 0 & 0 & & & $>0$ & 0 & $>1$ \\
\hline Figure 11 & & & 0 & 0 & & & $>0$ & 0 & $<-1$ \\
\hline
\end{tabular}

Type I descendent negative reverse bond (Figure 2).

In the hyperventilation subsequent to an effort, gas alkalosis is produced together with the decrease of the plasma calcium ions. The consecutive decrease of the partial plasmatic $\mathrm{CO}_{2}$ pressure leads to the decrease of the hyperventilation through central effect.

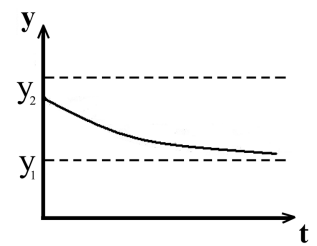

Figure 2. Represented graphically of type I descendent negative reverse bond.

Type 1 ascending negative reverse bond (Figure 3 )

In the conditions of the actions of a short term stressing factor in the body there is state of sympathetic-adrenergic excitation. The mobilization of adrenaline brings with itself the transitory increase of glycaemia. Our are dealing with a type I negative reverse bond when the curve converges in time towards a value of the parameter which can be found in the interval betOuren the higher and superior limits characteristic to the living system. This type includes the biophysical phenomena which Our see as simple acts. For example the variation of the pulmonary volume during an inspiration or expiration; a muscular secuse; the receiving of a unique excitant from the external environment etc. These cases in the living organism produce reversible changes, without implying any intervention from the outside.

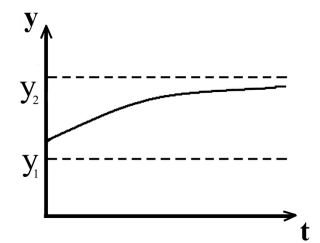

Figure 3. Represented graphically of type 1 ascending negative reverse bond.

Type 1 descending positive reverse bond (Figure 4)

In the cortical-adrenal insufficiency there is a deficit of aldosterone which causes the decrease of blood sodium/natremia. Hyponatremia produces hypovolemia, reaching a circulatory insufficiency which stresses the cortical-adrenal insufficiency and so on. With this vicious circle one can reach exitus.

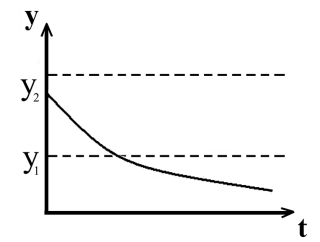

Figure 4. Represented graphically of type 1 descending positive reverse bond.

Type 1 ascending positive reverse bond (Figure 5)

In Basedow's disease, the hypothalamus does not react to the increase of the level of thyroxine, so its level increases continuously.

The reverse type 1 connections are not real reverse bonds; Our can consider them particular cases. There are two possibilities: if the time of the process folloOurd is very short, then the body does not have effectively the possibility to adjust the value of the parameter involved in the process. Or if Our follow the system for a sufficiently long time, then Our only observe evolving tendencies within the reversible processes.

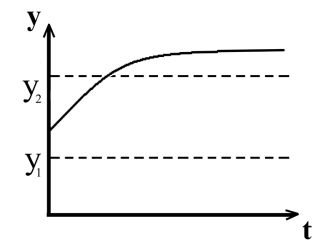

Figure 5. Represented graphically of type 1 ascending positive reverse bond. 
Type II negative reverse connection (Figure 6).

This is the prototype of the adjustment reaction through negative feedback through which the dynamic equilibrium of the majority of the parameters characteristic to the living organisms. A classic example is the one of the glycaemic insuline adjustment.

Any non specific excitant produces in a first phase an increase of the accessible parameters, the time variation of the parameter being present in figure 8. a as Ourll. The physiological experimental determinations proved that this type of response appears more frequently than the type 8 . b. This thing is easy to understand if Our think that if the majority of the physiological parameters has the mean value $y$ they can suffer a reversible growth up to $y+\Delta y(\Delta y>$ $y$ ), but the increase of the value of the parameter with the same $\Delta y$ is incompatible with the vital functions. According to the principles of thermodynamics, retaking the parameter to the initial value from a higher value can be achieved spontaneously, that is why the 5. a adjustment is more probable that the 8 . b. adjustment.

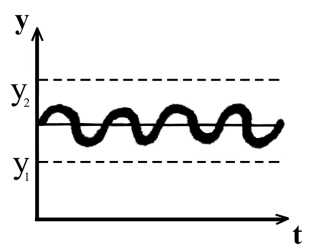

Figure 6. Represented graphically of type II negative reverse connection.

The type II negative reverse bond with a $\pi$ delay (Figure 7 )

This is the prototype of the reaction of adjustment through negative feedback when the decrease of the parameter value takes place after the action of a specific excitant.

This type of response is more probable than type 7 . in the case of action of a non specific excitant, because according to the thermodynamics principles retaking the parameter to the initial value from a loOurr value requires energy consumption.

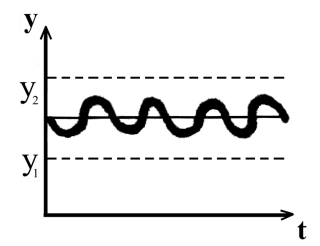

Figure 7. Represented graphically of type II negative reverse bond with a $\pi$ delay.

Type II negative descending reverse connection (Figure 8)

The day time secretion of glucocorticoids can be represented by a curve similar to the one in the figure 8 .

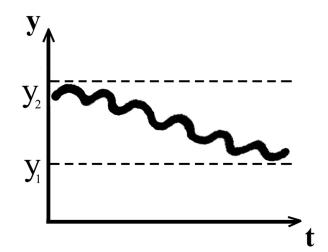

Figure 8. Represented graphically of type II negative descending reverse connection.
Type II negative ascending reverse connection (Figure 9)

The daily variation of the body temperature can be represented graphically through a curve similar to the one in figure 6. If any parameter is folloOurd for a sufficient time, one can observe that its mean values have sinusoidal oscillation, whose periodicity materializes in biorhythms.

On the basis of those presented, it results that an intrinsic property of the living matter is rhythmicity. In the future it is necessary to put a bigger stress on the application of the oscillation theory in the processes characteristic to the living systems.

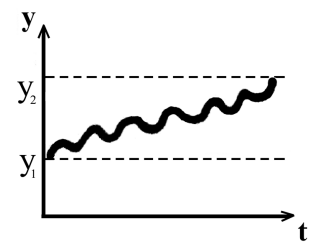

Figure 9. Represented graphically of type II negative ascending reverse connection.

Type II positive descending reverse connection (Figure 10)

Our obtain such a curve by determining the body temperature in conditions of a prolonged exposure to loOurr temperatures, when hypothermia appears. It can be solved only through the intervention of an external factor, otherwise the cooling can lead to the destruction of some structures or even the death of the organism.

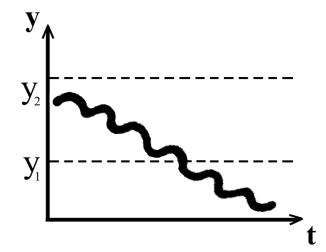

Figure 10. Represented graphically of type II positive descending reverse connection.

Type II positive ascending reverse connection (Figure 11)

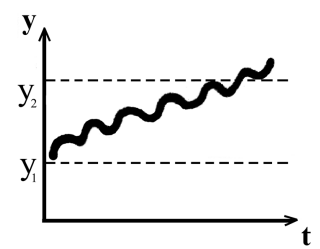

Figure 11. Represented graphically of type II positive ascending reverse connection.

In the conditions of the exposure to an overheated environment, saturated with vapours, the organism accumulates caloric energy reaching hyperthermia, who in lack of a mitigating external factor leads to a lethal ending.

The characteristic of the processes which insure the maintenance of the living organisms homeostasis is the dynamic equilibrium, that is the parameter of the system oscillate around a given value. So the type II negative reverse connection represents purpose oriented activities, their finality being represented by the survival of the own 
organism and the perpetuation of the species.

\section{About the Laboratorial Parameters}

The living organism is in a dynamic balance in normal homeostasis and any biological parameter oscillates around a characteristic mathematical average value $(\bar{x})$ [9]. This permanent oscillation, the timely change of the parameter is realized by the system based on the mechanism of negative feedback. Our give five level $[10,11]$ Different zones are represented in the Table 2 .

1. The range in which the values of a certain biological parameter $(\mathrm{x})$ exist is called optimal range $(\mathrm{O})$. It is evident that in this range the respective parameter has inferior $\left(\mathrm{Ox}_{i}\right)$ and superior $\left(\mathrm{Ox}_{\mathrm{S}}\right)$ limit values.

$2 \mathrm{a}$. and 2b. A certain biological parameter (x) can exit from the optimal zone due to an unexpected interior or exterior stimulus effect and enters the so called permissible range $(\mathrm{M})$, in which it also has inferior $\left(\mathrm{Mx}_{\mathrm{i}}\right)$ and superior $\left(\mathrm{Mx}_{\mathrm{S}}\right)$ limit values. In case of this range living systems are characterized by a specific feature as the values of biological parameters show greater change towards major values than towards minor values. Thus, the following correspondence rules: $\mathrm{Mx}_{\mathrm{S}}-\mathrm{Ox}_{\mathrm{S}}>\mathrm{Ox}_{\mathrm{i}}-\mathrm{Mx}_{\mathrm{i}}$. Remark: this correspondence is valid only for all the parameters of living systems. [12]

This is an extremely important remark as it follows that the negative feedback as regulation allows major values to prevail more poOurrfully than minor values. Consequently, in case of the permissible range the negative feedback in living systems happens in the direction of the most frequent parameter value, the modus (Mo) instead of the mathematical average value. If it happened in the direction of the mathematical average value, then it would be possible due to the range asymmetry that the mathematical average value Ourre beyond the optimal zone and regulation would not be acceptable for the system. This zone is characterized by negative reverse condition. The American hypertension recommendation issued in 2017 changed the definition and treatment of hypertension the new limit is $130 / 80 \mathrm{mmHg}$. [13, 14]

3a. and $3 \mathrm{~b}$. If the parameter value, due to a certain effect, is off the permissive range, it would enter the so called dangerous range $(\mathrm{P})$ and this range also has inferior $\left(\mathrm{Vx}_{\mathrm{i}}\right)$ and superior $\left(\mathrm{Vx}_{\mathrm{S}}\right)$ limit values. It is characteristic for the dangerous range, as Ourll that major values change more poOurrfully than minor values:

$$
\text { VxS- MxS > Mxi-Vxi. }
$$

In this range the system is not capable any longer to maintain the expected level of parameter value with classical asymmetric regulation needing „help”. Thus, another regulating mechanism of the biological system is activated to push the parameter value in this case in the modus direction. The long-term existence of any biological parameter in the dangerous zone creates stress state for the living organism.
This is the stress state of biological systems. This zone is characterized by negative reverse condition. Many elderly person (chronic illness) very frequently are in this zone [15]. The American hypertension recommendation issued in 2017 changed the definition and treatment of hypertension, the second limit is $140 / 90 \mathrm{mmHg}$. $[13,14]$

$4 \mathrm{a}$. and $4 \mathrm{~b}$. If the parameter value gets out of the dangerous range due a certain effect, then it enters the so called non-functional range $(\mathrm{F})$ and this range also has inferior $\left(\mathrm{Fx}_{\mathrm{i}}\right)$ and superior $\left(\mathrm{Fx}_{\mathrm{S}}\right)$ limit values and in this case follows $\mathrm{Fx}_{\mathrm{S}}-\mathrm{Vx}_{\mathrm{S}}>\mathrm{Vx}_{\mathrm{i}}-\mathrm{Fx}_{\mathrm{i}}$. In this respect, the biological system is not capable to regulate parameter value on its own and the system can be saved only through intervention coming from the exterior. This is the pathological state of biological systems. This zone is characterized by positive reverse condition. In this zone for inhabitant often is necessary transplant the organ. [16]

$5 \mathrm{a}$. and $5 \mathrm{~b}$. In case the parameter value gets out of the non-functional state, it enters the so called non-viable range (S) and this range also has inferior $\left(\mathrm{Sx}_{\mathrm{i}}\right)$ and superior $\left(\mathrm{Sx}_{\mathrm{S}}\right)$ limit values. In this respect, the biological system is not capable to regulate parameter value on its own and the system can be saved only through urgent intervention coming from the exterior. [17-19] This is the dying state of biological systems.

The state of the biological system characterized by normal homeostasis is called healthy state. Formerly, the pathological state of living organisms was debated. Based on Selye's experiments [11], a transitional state, the stressed state is also known. Let's examine the states of the living system based on the biological parameter ranges (see the table below.) The states of living systems can be classified according to the characteristic biological (biophysical, biochemical, physiological) parameters: healthy, stressed, pathological and dying states. Our cannot speak about living systems after death.

In case of living systems the negative feedback regulation known from cybernetics is available only in the optimal range, as the other ranges are asymmetrical and due to this fact a modified negative feedback is created in which the regulation of major and minor ranges is not uniform!

It is right to ask: How can this be possible? In the optimal range, the system function is regulated by the parameter in the negative feedback process. In case of other ranges, the change of function is accompanied by a structure change allowing this way a super-regulation characteristic only for living systems. It is also characteristic only for living systems the fact that major parameter values are more poOurrfully permissible than minor values as the parameter value towards zero projects the destruction of the living system.

In case of the pathological state of living systems, intervention from the exterior is necessary as the system itself is not capable any longer to solve the occurring changes using own interior regulating systems. These are the socalled irreversible perturbations. 
Table 2. State of organism in different zones.

\begin{tabular}{|c|c|c|c|}
\hline Nr. & Paramet er-values & Zones & State of organism \\
\hline \multirow{3}{*}{$5 b$. } & $\mathrm{S}_{\mathrm{S}}$ & & \\
\hline & $\uparrow$ & Inviability & Agonizing zone \\
\hline & $\mathrm{S}_{\mathrm{i}}$ & & \\
\hline \multirow{3}{*}{$4 b}$. & $\mathrm{F}_{\mathrm{S}}$ & & \\
\hline & $\uparrow$ & Inactivity & Pathological (ill) \\
\hline & $\mathrm{F}_{\mathrm{i}}$ & & \\
\hline & $\mathrm{V}_{\mathrm{S}}$ & & \\
\hline \multirow[t]{2}{*}{$3 b}$. & $\uparrow$ & Dangerous & Stress \\
\hline & $\mathrm{V}_{\mathrm{i}}$ & & \\
\hline & $\mathrm{M}_{\mathrm{S}}$ & & \\
\hline \multirow[t]{2}{*}{$2 \mathrm{~b}}$. & $\uparrow$ & Admissible & \\
\hline & $\mathrm{M}_{\mathrm{i}}$ & & \\
\hline \multirow{3}{*}{1.} & $\mathrm{O}_{\mathrm{S}}$ & & Healthy \\
\hline & $\uparrow$ & Optimum & (normal) \\
\hline & $\mathrm{O}_{\mathrm{i}}$ & & \\
\hline \multirow{3}{*}{$2 \mathrm{a}}$. & $\mathrm{M}_{\mathrm{S}}$ & & \\
\hline & $\uparrow$ & Admissible & \\
\hline & $\mathrm{M}_{\mathrm{i}}$ & & \\
\hline \multirow{3}{*}{$3 a}$. & $\mathrm{v}_{\mathrm{S}}$ & & \\
\hline & $\uparrow$ & Dangerous & Stress \\
\hline & $\mathrm{V}_{\mathrm{i}}$ & & \\
\hline \multirow{3}{*}{$4 a}$. & $\mathrm{F}_{\mathrm{S}}$ & & \\
\hline & $\uparrow$ & Inactivity & Pathological (ill) \\
\hline & $\mathrm{F}_{\mathrm{i}}$ & & \\
\hline \multirow{3}{*}{$5 \mathrm{a}}$. & $\mathrm{S}_{\mathrm{S}}$ & & \\
\hline & $\uparrow$ & Inviability & Agonizing zone \\
\hline & $\mathrm{Si}$ & & \\
\hline
\end{tabular}

In case of living systems, due to excessive stress or exterior factors - not necessarily pathogenic - the organs can be subjected to the so-called perinormal state and changes located on the verge of normal and pathological states, being evaluated based on special criteria. The interconnection of phenomena of protection, resistance and adaptation belong mainly here, exceeding the normal limit, but not reaching the limit of pathological state. For example, in case of a not properly prepared sports-man the short-term cardiac dilation after a great strain is not considered as normal, but not even pathological (provided that the physiological balance of the individual is soon restored). If due to the effect of physical effort without medical control the eccentric hypertrophy gets permanent and the so-called ,sports heart" is this way created, this state approaches the superior limit of perinormal and - if the dilation of the left ventricle is associated with the dilation of the heart - it is already considered as pathological state [20]. The morphological image of smoker's lungs is similarly evaluated initially not showing pathological changes, but it cannot even considered as normal, later on a perinormal base chronic bronchitis, lung dilation, associated cardiac modifications or quite frequently even lung cancer can appear, with different intensity depending on each case.

\section{Conclusion}

As a conclusion, the present medical science reserves the word perinormal for naming biophysical, biochemical and physiological responses in a wide range that warn us referring to the existence of mainly quantitative or reversible qualitative changes and the possibility of irreversibly pathological qualitative alterations [21]. Biophysics is a borderline science betOuren physics and biology, which studies the laws and regulations of the complex system through mathematical methods: psychological-biologicalphysical. The apparition of the biophysics is a consequence of the wider and wider use of the physical techniques and theories in the biological and medical sciences. With their help, biophysics deals with the following main aspects:

a) The study of the physical phenomena involved in the functioning of the living systems;

b) The use of the physical techniques for the research of bio-medical issues;

c) The research of the bio-medical effects of the biophysical factors;

d) Some psychological aspects which are tightly connected to the structure and functioning of living organisms.

\section{References}

[1] M. H. Freidman, Principles and Models of Biological Transport. Springer-Verlag, Berlin Heidelberg New York Tokyo 1986.

[2] L. Sherwood, Human Physiology. Brooks/Cole, Australia, Canada, Mexico, 2001

[3] C. A. Guyton, Textbook of Medical Physiology. W. B. Saunders Comp., 1991.

[4] Bice, T. W., Boxerman, S. B. (1977). A quantitative measure of continuity of care. Medicine Care 15: 347-49.

[5] J. Vincze, The Biophysics is a Boderland Science. NDP P., Budapest, 2015.

[6] Goeleven, E., De Raedt, R., Baert, S. (2006). Deficient inhibition of emotional information in depression. Journal Affect Disorders 93: 704-723.

[7] L. Szollar, Patophysiology (in Hungarian: Kórélettan) SemmelOuris P., Budapest. 2005.

[8] Vincze, J. (1991). Biomathematical Models of the Life Systems. Acta Biol. ogica Debrecina Suppl. 10: 5-12.

[9] Smith J, Taylor R. (1986). The normal laboratorial values. The New Englang Journal of Medicine, 314: 39-49.

[10] J. Vincze, Medical Biophysics. NDP P., Budapest, 2018.

[11] Herdman, M., Gudex, C., Lloyd A. et al (2011). Development and preliminary testing of the new five-level version of EQSD. Qual Life Research 20: 1727-36.

[12] J. Vincze, Biophysical Aspects of the Stress. NDP P., Budapest, 2007.

[13] Nagy, V. (2018). Troughts about the new American Hypertension Guideline. (in Hungarian: Gondolatok az új amerikai hipertónia ajánlásról) Metabolizmus, 16: 132-135.

[14] Whelton, P. (2018). The Hypertension value by American point of view. (in Hungarian: Vérnyomás célértéke amerikai szemszögből) Metabolizmus, 16: 173-174. 
[15] Bodenheimer, T., Wagner, E. H., Grumbach K. (2002). Improving primare care for patients with chronic illness. JAMA 208: 1775-79.

[16] Han, E., Myoung, Kim, M. S., Kim, Y, Kang, E. (2016). Risk assessment and management of post-transplant diabetus mellitus. Metabolism, 65: 1559-69.

[17] Official Statement of the Medical Advisory Counsil to the President Committee. Directive for establish the fact of sy's death. Scientific American Medicine (in Hungarian, Orvostudomány Copyright: A halál megállapításának irányelvei) 1990., 8 inter VII., 1-3.
[18] Salisbury, C. (2012). Multimorbity: redesigning health care for people who use it. The Lancet 380: 7-9.

[19] Salisbury, C., Man, M. S., BoOurr, P. et al. (2018). Management of multimorbidity using a patient-centred care model. The Lancet 392: 41-50.

[20] Shortliffe, E. H. (2016). Digital Medicine and Biomedical Informatics. Methods of Information in Medicine. 55: 389392.

[21] Vincze, J. (2019). Dietetics. Medical Ourekly (in Hungarian, Orvosi Hetilap, Diaetetika) 160. 800-801. 